\title{
Safety and success rate of vaginal birth after two cesarean sections: retrospective cohort study
}

\author{
Jan Modzelewski ${ }^{1,}$, , Monika Jakubiak-Proc ${ }^{1,2}$, Anna Materny ${ }^{2}$, Maria Sotniczuk², \\ Anna Kajdy1, 2 , Michal Rabijewski ${ }^{1}$ \\ ${ }^{1}$ Department of Reproductive Health, Centre of Postgraduate Medical Education, Warsaw, Poland \\ 2Żelazna Medical Centre, St. Sophia Specialist Hospital, Warsaw, Poland
}

\begin{abstract}
Objectives: Cesarean section is a lifesaving procedure with short and long-term consequences. Growing rates of cesarean sections worldwide arise problems for subsequent birth. The aim of this study was to compare safety of vaginal birth after two cesarean sections with repeat third cesarean section to help healthcare providers and patients make well informed decisions about mode of subsequent delivery.

Material and methods: This was a retrospective cohort study conducted in a tertiary reference hospital. Database of all deliveries (2010-2017) after two previous cesarean sections was created from electronic and paper medical records. Preterm deliveries, abnormal karyotype and neonates with congenital anomalies were excluded from the study. The final analysis included 412 cases for maternal outcome analysis and 406 cases for neonatal outcome analysis.

Results: Trial of labor after two cesareans in comparison to repeat cesarean section increases the risk of hemorrhage (OR: 10.84) and unfavorable composite maternal outcome (OR: 2.58). Failed trial of labor increases this risk of hemorrhage (OR: 15.27) and unfavorable composite maternal outcome (OR: 4.59) even further. There were no significant differences in neonatal outcomes. 22 out of 35 trials of labor ended in successful delivery giving a success rate of $62.85 \% .5$ of 7 labor inductions ended in repeat cesarean section giving $28.6 \%$ success rate. There were no maternal deaths and emergency hysterectomies. Conclusions: Trial of labor, especially failed trial of labor, is associated with an increased risk of perinatal complications. Key words: vaginal birth after two cesareans; cesarean section; trial of labor; uterine rupture; obstetric labor complications
\end{abstract}

\section{INTRODUCTION}

Cesarean section is a well-established surgical technique when vaginal delivery carries a substantial risk for the mother or baby or is otherwise contraindicated. Despite obvious benefits it may pose serious short and long-term consequences $[1,2]$

Cesarean section rates are increasing worldwide, being as high as $55 \%$ in some regions. The current rate of cesarean delivery in Poland is 36.1\% [3-6]. Women with a previous cesarean section decide on having another child regardless of the documented higher risks of such pregnancy $[7,8]$. Choosing the right mode of delivery is a challenge for the mother and healthcare provider. Both vaginal delivery after cesarean and repeat cesarean delivery (RCS) are associated with maternal complications [9-13]. Risk of most maternal complications increases proportionally to the number of cesarean sections $[14,15]$. Whether or not trail of labor after two cesarean sections (TOLAC-2) increases neonatal mortality is still to be established. [16-18].

Obstetric colleges worldwide, including Polish, recommend trial of labor after one cesarean and state that trial after two cesareans is not contraindicated [19-21].

\section{Objectives}

The aim of this study was to make a pragmatic comparison of TOLAC- 2 and RCS. These results may help clinicians and women make informed decisions about delivery route. The main thesis of this study was that TOLAC- 2 carries no greater risk than RCS.

\section{MATERIAL AND METHODS}

Anonymous electronic records of all 47,011 singleton deliveries between 2010-2017 were extracted from the hospital patient management system. 432 records of women with pre- 
vious two cesarean deliveries were identified, and individual paper records were analyzed to extract data unavailable in electronic records. Predefined exclusion criteria for maternal outcome were: preterm deliveries (17 cases), placenta previa (3 cases). 412 cases were included in the maternal analysis. Predefined exclusion criteria for neonatal outcome were: abnormal karyotype, major congenital anomalies (definition: EUROCAT Guide 1.4) [22]. 406 cases were included in the neonatal analysis. Data extraction process is shown on Figure 1.

The cohort was divided into two groups depending on intended mode of delivery: TOLAC-2 and RCS. Each group was additionally divided into two subgroups. TOLAC-2 was divided into successful vaginal delivery after two cesareans (VBAC-2) and failed TOLAC-2. RCS was divided depending on timing of procedure - as scheduled and unscheduled (i.e. preformed before planned operation date, exclusively because of onset labor).

Safety and success rate of VBAC-2 was the main focus of the analysis. Analyzed maternal outcomes were maternal death, postpartum hemorrhage, hysterectomy, uterine rupture, need for blood products transfusion, bladder or bowel injury. The outcomes were analyzed separately, given their relative scarcity, and in combination as composite maternal outcome. There is no CROWN core outcome set for trial of labor.

Uterine rupture was defined as any detected cesarean scar dehiscence, independently of size or clinical symptoms. A retrospective study did not allow for reliable discrimination between symptomatic uterine rupture and asymptomatic uterine scar dehiscence. Postpartum hemorrhage was defined as estimated blood loss of $500 \mathrm{~mL}$ after vaginal or $1000 \mathrm{~mL}$ after cesarean delivery, as defined by World Health Organisation (WHO) [23].

The medical records were searched for information on use of the Bakri balloon, curettage or additional operative procedures afterVBAC-2. Additionally, cesarean section protocols were searched for information on use of additional sutures or other surgical intervention to stop bleeding. Each of the described were categorized as need of additional hemostatic procedures even if blood loss did not meet criteria

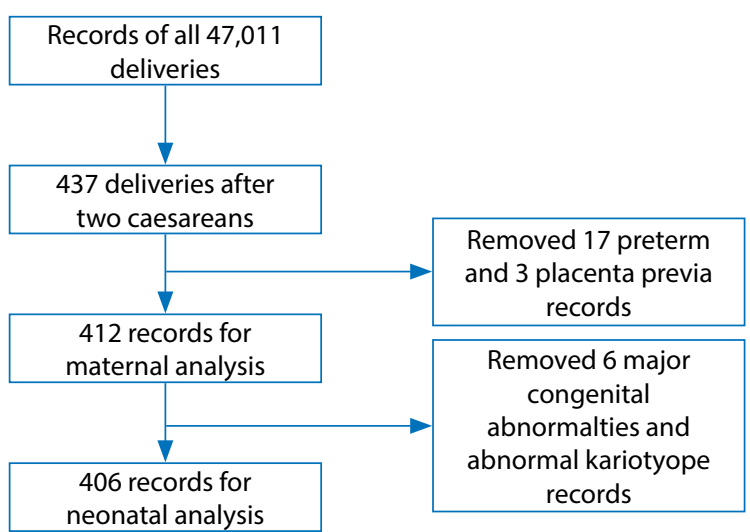

Figure 1. Data extraction process for hemorrhage. Patient documentation did not specify if use of additional uterotonic, was prophylactic or treatment, making this analysis impossible.

Surgical complications were defined as intraoperative damage of bladder or intestine, postoperative hematoma, impaired wound healing or need for relaparotomy.

Composite maternal outcome was defined as occurrence of any mentioned above but uterine rupture. Uterine rupture was not included in the composite maternal outcome due to high risk of detection bias. If a woman had multiple outcomes, she was counted only once.

Length of hospital stay was calculated in full days using admission and discharge date and compared for subgroups.

Neonatal outcome was defined as 5-minute Apgar score $<7$, intraventricular hemorrhage, periventricular leukomalacia, hypothermia, seizures, neonatal sepsis, diagnosed birth asphyxia and neonatal death. They were analyzed separately and combined into composite neonatal outcome. Cord blood pH was not routinely tested making any comparisons likely to be biased.

Effort has been made to check consistency and completeness of database. If electronic and paper records data extraction yielded different results, then the records were double-checked and corrected. Database was checked for duplicate records. There was no missing outcome data.

\section{Statistical analysis}

Statistical calculations were performed using Microsoft Office Excel (Microsoft Corp., Redmond, USA) and R [R Development Core Team (2012). R: A language and environment for statistical computing. R Foundation for Statistical Computing, Vienna, Austria. ISBN 3-900051-07-0, URL http://www.R-project. org/]. The statistical analysis of odds ratio (OR) of the maternal and neonatal outcomes was performed on a basis of $X^{2}$ test and normal test (used as a basis for $p$-value estimation and assessment of statistical significance). Both normal and $x^{2}$ models resulted in consistent estimates. Confidence intervals $(\mathrm{Cl})$ for $\mathrm{OR}$ were derived on a basis of a normal model, assuming $95 \%$ level of confidence. For outcomes of uterine rupture in unscheduled RCS and need of transfusion in VBAC-2 subgroups, $p$-value calculated using $X^{2}$ model were equal to 0.048 and 0.047 respectively. In these two cases, the table presents $p$-values derived using normal model. The analysis of the statistical significance of the differences in blood loss between selected groups was performed on a basis of two sample t statistic, assuming 95\% level of confidence. All significance tests were two sided and conducted at the $5 \%$ significance level.

Bioethics Committee of the Centre of Postgraduate Medical Education approval (reference number 47/PB/2018) for this project was obtained on $11^{\text {th }}$ of April 2018. According to Polish law creation of an anonymous database does not need individual participants' agreement. 


\section{RESULTS}

Comparison of baseline characteristics of the studied population is presented in Table 1. We did not find significant differences in any of the analyzed variables including pregnancy complications (cholestasis of pregnancy, diabetes in pregnancy, pre-pregnancy hypertension and pregnancy hypertension - data not shown).

Success rates of VBAC- 2 were calculated among 35 women who underwent TOLAC-2. In this group 22 had a VBAC-2, there was no operative vaginal deliveries and 12 required an emergency cesarean section.

The number and percentage of women willing to undergo TOLAC-2 was similar in the years 2010-2016, with substantial rise in 2017. In 2017 there were 19 TOLAC-2 including 12 VBAC-2 (12,5\% of all deliveries after two cesareans) - see Figure 2 .

In the analyzed period there were 7 labor inductions after two cesareans, 4 with i.v. Oxytocin infusion, 1 with intracervical Foley catheter insertion and 2 with both methods used. Of those, 2 ended in vaginal birth, 3 in emergency cesarean section because of threating birth asphyxia, and 2 in cesarean section because of arrested first stage of labor. Remaining 28 TOLAC-2 patients where admitted to the hospital in the first stage of labor, there were no admissions during second stage of labor.

Maternal outcomes are presented in Table 2 ( $\mathrm{p}$-values delivered from normal model). Uterine rupture (11 cases)

Table 1. Baseline demographic characteristic of studied population

\begin{tabular}{|l|l|l|l|l|l|l|}
\hline & \multicolumn{4}{|l}{ Repeat caesarean section } & \multicolumn{2}{l|}{ Trial of labour } \\
\cline { 2 - 6 } & $\begin{array}{l}\text { Scheduled repeat } \\
\text { caesarean section }\end{array}$ & $\begin{array}{l}\text { Unscheduled } \\
\text { repeat caesarean } \\
\text { section }\end{array}$ & $\begin{array}{l}\text { Repeat } \\
\text { caesarean } \\
\text { section - total }\end{array}$ & VBAC-2 & Failed TOLAC-2 & $\begin{array}{l}\text { Trial of } \\
\text { labour }- \text { total }\end{array}$ \\
\hline Maternal age [years] & $35.35( \pm 3.86)$ & $34.35( \pm 4.77)$ & $35.25( \pm 3.96)$ & $32.45( \pm 4.27)$ & $33.85( \pm 3.26)$ & $32.97( \pm 3.97)$ \\
\hline Parity & $3.04( \pm 0.21)$ & $3.08( \pm 0,43)$ & $3.07( \pm 0.41)$ & $3.3( \pm 0.95)$ & $3.5( \pm 0.83)$ & $3.38( \pm 0.89)$ \\
\hline BMl at booking & $24.13 \pm 4.52$ & $22.38 \pm 3,99$ & $23,97( \pm 4.5)$ & $22.55 \pm 2.73$ & $22.79 \pm 1.75$ & $21.94( \pm 2.48)$ \\
\hline BMl at delivery & $28.92 \pm 4.41$ & $27.45 \pm 4.20$ & $28.79( \pm 4.41)$ & $26.34 \pm 3.11$ & $28.12 \pm 2.91$ & $26.98( \pm 3,12)$ \\
\hline $\begin{array}{l}\text { Weeks of pregnancy } \\
\text { (completed) }\end{array}$ & $38.5( \pm 0.71)$ & $38.06( \pm 0.94)$ & $38.39( \pm 0.74)$ & $39.91( \pm 0.92)$ & $40.00( \pm 1.08)$ & $39.88( \pm 1.09)$ \\
\hline Birthweight $[g]$ & $3,464.59( \pm 407)$ & $3,302.83( \pm 411.40)$ & $3,449( \pm 409)$ & $3,760.68( \pm 392.50)$ & $3,886.15( \pm 448.75)$ & $3,807( \pm 412)$ \\
\hline
\end{tabular}

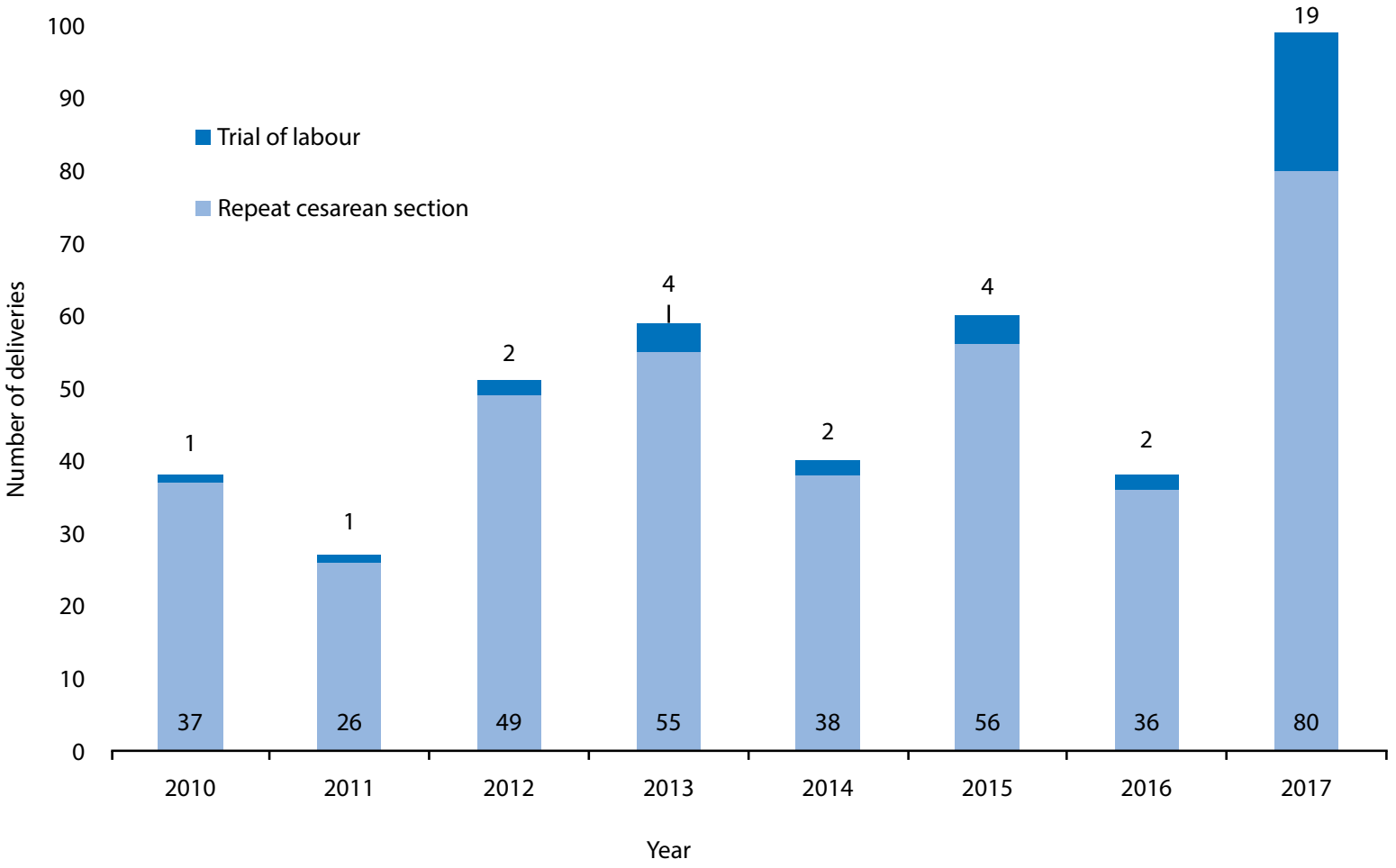

Figure 2. Frequency of trial of labor after two cesareans 


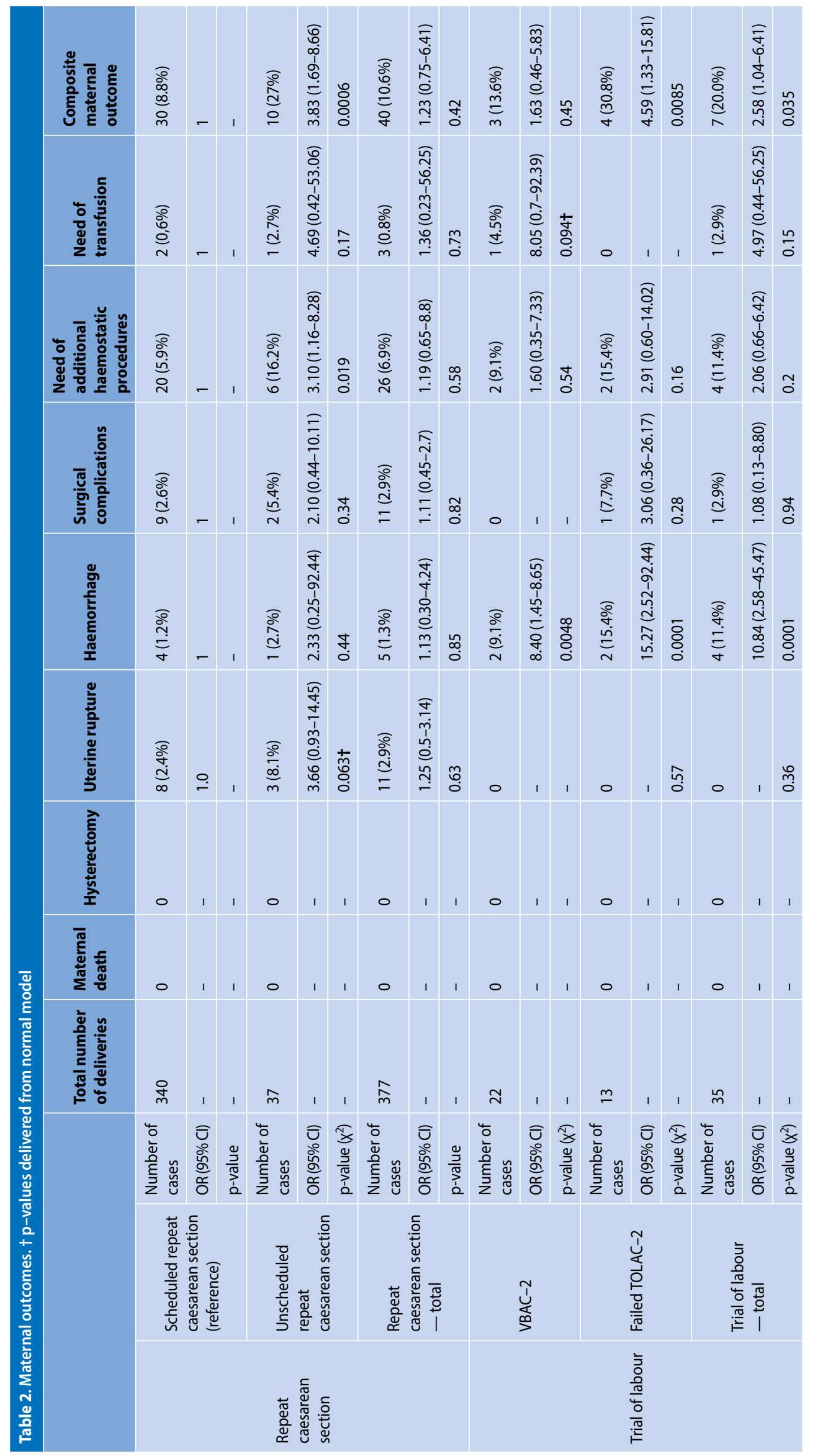


was exclusively detected during cesarean section. Each VBAC-2 individual had digital examination of cesarean scar after delivery and no dehiscence was found. None of $12 \mathrm{ce}-$ sarean sections in the failed TOLAC-2 group was conducted because of presumed scar dehiscence, also no scar dehiscence was found in this group during surgery.

VBAC-2 subgroup had lowest mean estimated blood loss, followed by scheduled RCS, failed TOLAC- 2 and unscheduled RCS. In comparison to scheduled RCS subgroup, the risk of hemorrhage was highest in failed TOLAC-2, followed by VBAC-2 and unscheduled RCS. Need for additional hemostatic procedures, compared to scheduled RCS was highest in unscheduled RCS, followed by failed TOLAC- 2 and VBAC-2 subgroup. We have found two cases of incomplete placenta in VBAC-2 group, one of them was the reason for maternal hemorrhage. Second case of bleeding occurred because uterine subatony.

Risk of transfusion after TOLAC-2 was higher than after RCS but the result was statistically insignificant. The identified surgical complications were exclusively related to cesarean section. Of 377 women in RCS group 11 had surgical complications. In failed TOALC-2 group one woman had surgical complications during cesarean section. Relaparotomy had to be performed in two cases, one because of intrabdominal hemorrhage (scheduled RCS subgroup), second because of bladder injury (unscheduled RCS subgroup).

Composite maternal outcome showed higher risk of complications in TOLAC-2 group. However, VBAC-2 sub- group comparison with scheduled RCS showed no statistically significant difference in VBAC-2 safety. Failed TOLAC-2 and unscheduled RCS composite maternal outcome where both higher than reference scheduled RCS. Maternal outcomes were compared in an intention-to-treat analysis, showing much higher risk of hemorrhage in TOLAC-2 group. Mean hospitalization time in RCS was 4.45 days and 3.80 days in TOLAC-2. Odds ratios for each outcome are shown on Figure 3.

Neonatal outcomes (Tab. 3) were analyzed separately and combined into composite neonatal outcome. Neither of the individual neonatal outcomes nor composite neonatal outcome reached statistical significance. We did not observe 5-minute Apgar score $<7$, intraventricular hemorrhage, periventricular leukomalacia, hypothermia, neonatal sepsis and neonatal death in our cohort (data not shown).

Maternal outcomes from intention-to-treat, planned TOLAC-2 or RCS, are presented in Table 4. ITT analysis showed greater risk of hemorrhage in TOLAC-2 patients but did not show difference for other analyzed outcomes.

No maternal death or hysterectomy took place in our cohort; thus, we were not able to analyze those outcomes.

\section{DISCUSSION}

Our findings suggest that vaginal birth after two cesareans carries a higher risk to mother and has no effect on the neonate. We did not find increased risk of uterine rupture

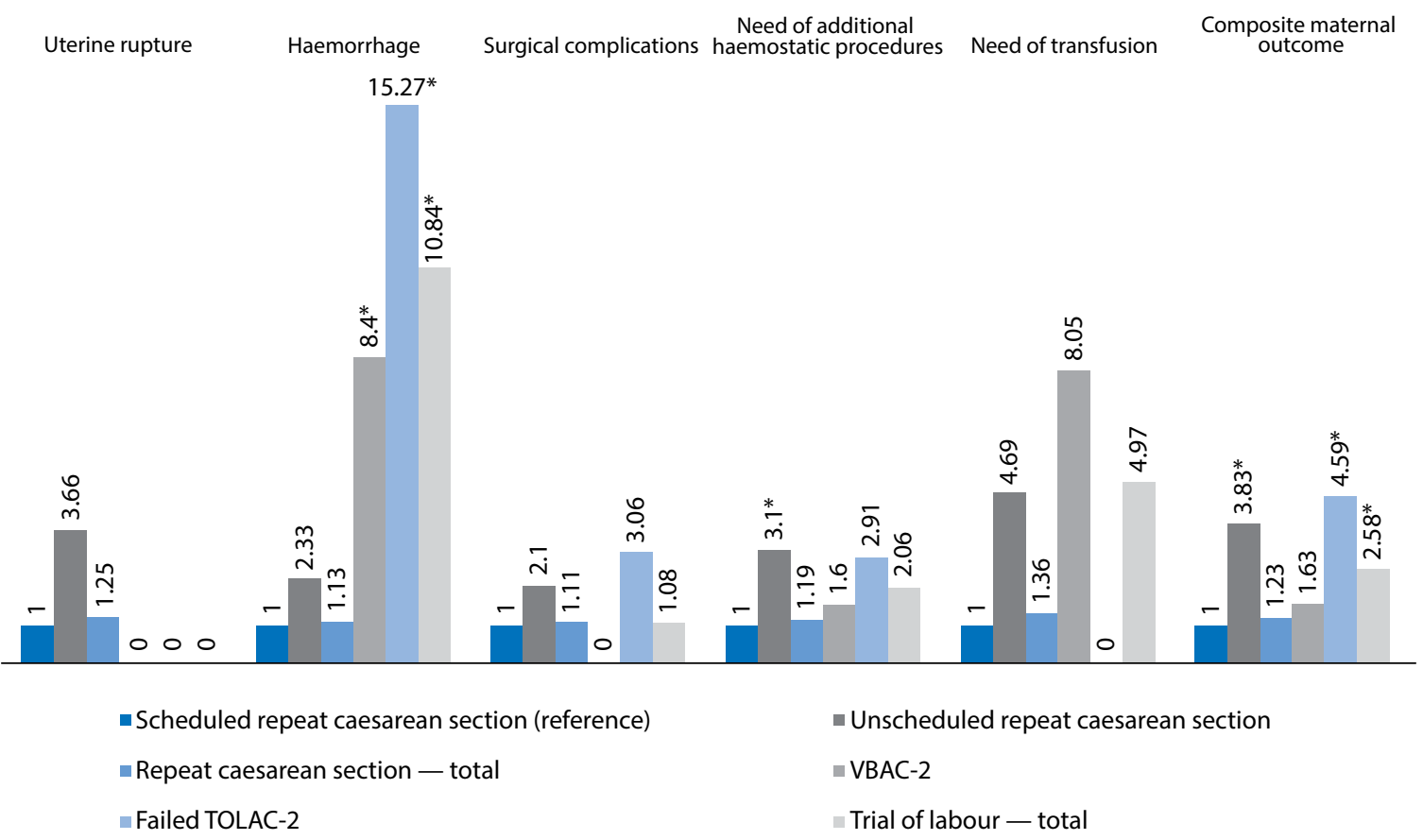

Figure 3. Odds ratio for maternal complications. Scheduled repeat caesarean section as reference; VBAC-2 - vaginal birth after two cesareans, TOLAC-2 - trial of labor after two cesareans; * Statistically significant 




during trial of labor, but risk of hemorrhage was very high. Composite maternal outcome risk was also higher in TOLAC-2 group, especially in failed TOLAC-2. Therefore, good qualification for vaginal birth is essential for decreasing trial of labor complications. Trial of labor has a high enough success rate to justify recommending it to the patient.

We tried to select all clinically relevant outcomes. Need of use of uterotonic drugs to treat hemorrhage was one of the selected outcomes, but paper and electronic records did not contain enough data to reliably allow such analysis. All other selected outcomes data is provided, even if the analysis yielded insignificant results.

Electronic and paper records where cross-checked, minimalizing risk of error.

Limitation of this study is its retrospective character. Differentiation between uterine scar dehiscence and rupture or if use of uterotonics was prophylactic or for treatment purposes was impossible.

During study time there were total 47011 births and only 35TOLAC-2. This is probably an effect of low patient awareness of VBAC-2 availability, healthcare provider reluctance to propose trial of labor after two cesarean sections because of fear of complications and medico-legal issues. To our knowledge there are no Polish trials trying to establish to what extent each cause is responsible for this situation. International studies emphasize healthcare provider view on complications, medico-legal problems, better"predictability" of RCS, patient anxiety [24, 25]. Rise of number of TOLAC-2 in 2017 was probably an effect of widespread information of Hospital policy in social media.

The risk of uterine rupture in this study was $2.67 \%$ and is similar to uterine rupture rate in work of Caughey et al. [26], Macones et al. [9] and by Landon et al. [27]. Metanalysis byTahseen and Griffiths show risk of uterine rupture of 1.36\% [10]. In the studied cohort all uterine ruptures were detected during cesarean section. Detection of scar dehiscence is rare with transcervical digital scar revision [28, 29]. Gamer et al. also reported a high risk of detection bias in a trial scoped for detecting uterine rupture by transcervical manual control [29]. Results obtained by Spaans et al. [30] with uterine scar dehiscence detected mostly during cesarean section show similar pattern to this study.

Risk of postpartum hemorrhage was the most prominent difference between mode of delivery groups. Risk of substantial blood loss is much higher in trial for labor group. Current literature review shows there is no study describing the rate of postpartum hemorrhage in TOLAC-2. Small numbers make drawing conclusions difficult but we think that changed uterine architecture and altered contraction mechanics could be responsible for increased blood loss, especially in failed TOLAC-2 where changes are probably the greatest.

Study by Macones et al. [9] and metanalysis of Tahseen and Griffiths [10] show VBAC-2 to have a lower risk of transfu- 
Table 4. Maternal outcome regarding intended mode of delivery

\begin{tabular}{|c|c|c|c|c|c|c|}
\hline & \multicolumn{3}{|l|}{ RCS (reference) } & \multicolumn{3}{|l|}{ TOLAC-2 } \\
\hline & Number of cases & OR (95\% Cl) & $\mathbf{p}$ & Number of cases & OR (95\% Cl) & p \\
\hline Haemorrhage & $5(1.3 \%)$ & - & - & $4(11.4 \%)$ & $9.6(2.45-37.59)$ & 0.0001 \\
\hline Surgical complications & $11(2.9 \%)$ & - & - & $1(2.9 \%)$ & $0.98(0.12-7.81)$ & 0.98 \\
\hline $\begin{array}{l}\text { Need of additional haemostatic } \\
\text { procedures }\end{array}$ & $26(6.9 \%)$ & - & - & $4(11.4 \%)$ & $1.74(0.57-5.31)$ & 0.32 \\
\hline Need of transfusion & $3(0.8 \%)$ & - & - & $1(2.9 \%)$ & $3.67(0.37-36.22)$ & 0.23 \\
\hline Composite maternal outcome & $40(10.6 \%)$ & - & - & $7(20 \%)$ & $2.11(0.86-5.13)$ & 0.095 \\
\hline
\end{tabular}

sion. The presented study found a contradictory result but did not reach statistical significance.

In this cohort the risk of surgical complications was two times higher for unscheduled RCS and three times higher in cesarean section because of failed TOLAC-2. Although the results were not statistically significant, they are consistent with results presented by Silver et al. [31] and Phipps et al. [32].

Composite maternal outcome analysis showed that vaginal birth after two cesareans is associated with a 2.58 higher risk of complications, similar to that reported by Macones et al. [9] Although a 2.58 increase in risk is considered high it has to be kept in mind that patients who underwent TOLAC-2 were very motivated. However, a higher risk of complications is mainly related to failed trial of labor while complications of successful VBAC-2 are much less frequent. Intention to treat of intended mode of delivery complications showed increased risk of hemorrhage in TOLAC-2, without increased risk of other complications. This result needs emphasizing, as women and healthcare provider could decide about intended mode of delivery, not about actual mode of delivery.

A paper of Tahseen and Griffiths [10] quoted an overall success rate of $71.7 \%$, with individual studies varying from 45 to $83 \%$. In our cohort $62.85 \%$ of patients achieved vaginal birth.

No evidence was found to support the idea of increased neonatal morbidity or mortality after TOLAC-2. Such risk for delivery after one cesarean section is described in a paper of O'Neil et al. [16] but authors found substantial cohort effect, with risk decreasing over time, with no risk increase in the most recent period. Older work of Smith et al. [17] also describe much higher risk for perinatal death after trial of labor after cesarean comparing to RCS, but this data comes from years 1992-1997. The results of the presented study are similar to those reported by Menacker et al. in 1998-2002 cohort [33].

Current recommendations of obstetric colleges worldwide state that planned VBAC may be supported in women with two or more previous lower segment caesarean deliveries" - Royal College of Obstetrics and Gynaecology, "Given the overall data, it is reasonable to consider women with two previous low-transverse cesarean deliveries to be candidates for TOLAC" - American College of Obstetrics and Gynecology, "trial of labor in women with more than 1 previous Cesarean is likely to be successful but is associated with a higher risk of uterine rupture" - Polish Society of Obstetrics and Gynecology, "TOLAC (after two cesareans) is possible" - French National College of Obstetricians and Gynecologists [19-21, 34]. Encouragement from professional organizations could have an impact on graduate increase of TOLAC-2.

\section{CONCLUSIONS}

This study shows TOLAC-2 to be reasonable in terms of safety and has a good success rate. It is associated, especially failed TOLAC-2, with increased risks and women should be openly informed about them. In light of this study both VBAC-2 and RCS are high-risk procedures and should be performed only if highly trained personnel and resources are available.

From a practical point of view TOLAC- 2 is not of greater risk to the patient if it ends in vaginal delivery. Of course, healthcare provider could not foresee exactly if trial will be successful, but careful qualification for trial of labor could prevent at least some of the delivery complications.

\section{Acknowledgements}

Authors want to acknowledge Dorota Sys and Paweł Frączak for their support in this project and Radoslaw Bogucki for providing statistical analysis of data. Project had no external funding. The authors declare that they have no conflict of interests.

\section{REFERENCES}

1. Visser GHA. Women are designed to deliver vaginally and not by cesarean section: an obstetrician's view. Neonatology. 2015; 107(1): 8-13, doi: 10.1159/000365164, indexed in Pubmed: 25301178.

2. Gregory $K D$, Jackson $S$, Korst $L$, et al. Cesarean versus vaginal delivery: whose risks? Whose benefits? Am J Perinatol. 2012; 29(1): 7-18, doi: 10.1055/s-0031-1285829, indexed in Pubmed: 21833896.

3. Betrán AP, Ye J, Moller AB, et al. The Increasing Trend in Caesarean Section Rates: Global, Regional and National Estimates: 1990-2014. PLoS One. 
2016; 11(2): e0148343, doi: 10.1371/journal.pone.0148343, indexed in Pubmed: 26849801.

4. Health at a Glance 2017. Health at a Glance. 2017, doi: 10.1787/health glance-2017-en.

5. Wang $X$, Hellerstein $S$, Hou $L$, et al. Caesarean deliveries in China. BMC Pregnancy Childbirth. 2017; 17(1): 54, doi: 10.1186/s12884-017-1233-8, indexed in Pubmed: 28166782.

6. Chanrachakul B, Herabutya Y, Udomsubpayakul U. Epidemic of Cesarean Section at the General, Private and University Hospitals in Thailand. Journal of Obstetrics and Gynaecology Research. 2000; 26(5): 357-361, doi: 10.1111/j.1447-0756.2000.tb01339.x.

7. lyoke CA, Ugwu GO, Ezugwu FO, et al. Risks associated with subsequent pregnancy after one caesarean section: A prospective cohort study in a Nigerian obstetric population. Niger J Clin Pract. 2014; 17(4): 442-448, doi: 10.4103/1119-3077.134035, indexed in Pubmed: 24909467.

8. Taylor LK, Simpson JM, Roberts CL, et al. Risk of complications in a second pregnancy following caesarean section in the first pregnancy: a population-based study. Med J Aust . 2005; 183(10): 515-519, doi: 10.5694/j.1326-5377.2005.tb07152.x.

9. Macones GA, Cahill A, Pare E, et al. Obstetric outcomes in women with two prior cesarean deliveries: is vaginal birth after cesarean delivery a viable option? Am J Obstet Gynecol. 2005; 192(4): 1223-8; discussion 1228, doi: 10.1016/j.ajog.2004.12.082, indexed in Pubmed: 15846208.

10. Tahseen S, Griffiths M. Vaginal birth after two caesarean sections (VBAC-2)-a systematic review with meta-analysis of success rate and adverse outcomes of VBAC-2 versus VBAC-1 and repeat (third) caesarean sections. BJOG. 2010; 117(1): 5-19, doi: 10.1111/j.1471-0528.2009. 02351.x, indexed in Pubmed: 19781046.

11. Al-Shaikh G, Al-Mandeel $\mathrm{H}$. The outcomes of trial of labour after cesarean section following induction of labour compared to spontaneous labour. Arch Gynecol Obstet. 2013; 287(6): 1099-1103, doi: 10.1007/s00404-013-2709-z, indexed in Pubmed: 23307166.

12. de Lau H, Gremmels H, Schuitemaker NW, et al. Risk of uterine rupture in women undergoing trial of labour with a history of both a caesarean section and a vaginal delivery. Arch Gynecol Obstet. 2011; 284(5): 1053, doi: 10.1007/s00404-011-2048-x, indexed in Pubmed: 21879334.

13. Kostrzewa T, Walczak J, Wieckowska K. Vaginal birth after cesarean delivery. . Ginekol Pol. 2010; 81(4): 287-291.

14. Kaplanoglu M, Bulbul M, Kaplanoglu D, et al. Effect of multiple repeat cesarean sections on maternal morbidity: data from southeast Turkey. Med Sci Monit. 2015; 21: 1447-1453, doi: 10.12659/MSM.893333, indexed in Pubmed: 25989945.

15. Cintesun $E, A$ Al RA. The effect of increased number of cesarean on maternal and fetal outcomes. Ginekol Pol. 2017; 88(11): 613-619, doi: 10.5603/GP.a2017.0110, indexed in Pubmed: 29303215.

16. O'Neill SM, Agerbo E, Khashan AS, et al. Trial of labour after caesarean section and the risk of neonatal and infant death: a nationwide cohort study. BMC Pregnancy Childbirth. 2017; 17(1): 74, doi: 10.1186/s12884017-1255-2, indexed in Pubmed: 28241870.

17. Smith GCS, Pell JP, Cameron AD, et al. Risk of perinatal death associated with labor after previous cesarean delivery in uncomplicated term pregnancies. JAMA. 2002; 287(20): 2684-2690, doi: 10.1001/jama.287.20.2684, indexed in Pubmed: 12020304.

18. Obara H, Minakami H, Koike T, et al. Vaginal Birth after Cesarean Delivery: Results in 310 Pregnancies. Journal of Obstetrics and Gynaecology Research. 1998; 24(2): 129-134, doi: 10.1111/j.1447-0756.1998.tb00063.x.

19. Birth after Previous Caesarean Birth (Green-top Guideline No. 45). Royal College of Obstetricians \& Gynaecologists. https://www.rcog.org. uk/en/guidelines-research-services/guidelines/gtg45/ ( 2018 Mar 21).
20. Practice Bulletin No. 184: Vaginal Birth After Cesarean Delivery. Obstetrics \& Gynecology. 2017; 130(5): e217-e233, doi: 10.1097/00006250201711000-00051.

21. Poreba R, Brazert J, Chazan B, et al. [Polish Gynecological Society's recommendations regarding cesarean section]. Ginekol Pol. 2008; 79(5): 378-384, indexed in Pubmed: 18624116.

22. EUROCAT (2013). EUROCAT Guide 1.4: Instruction for the registration of congenital anomalies. EUROCAT Central Registry, University of Ulster . http://www.eurocat-network.eu/pagecontent.aspx?tree=aboutus/datacollection/guidelinesforregistration/guide1_4 (2018 Mar 22).

23. WHO Recommendations for the Prevention and Treatment of Postpartum Haemorrhage. Geneva: World Health Organization; 2012. (WHO Guidelines Approved by the Guidelines Review Committee). . http:// www.ncbi.nlm.nih.gov/books/NBK131942/ (2018 Feb 20).

24. Yeh J, Wactawski-Wende J, Shelton JA, et al. Temporal trends in the rates of trial of labor in low-risk pregnancies and their impact on the rates and success of vaginal birth after cesarean delivery. Am J Obstet Gynecol. 2006; 194(1): 144, doi: 10.1016/j.ajog.2005.06.079, indexed in Pubmed: 16389024.

25. Niino Y.The increasing cesarean rate globally and what we can do about it. Biosci Trends. 2011; 5(4): 139-150, doi: 10.5582/bst.2011.v5.4.139, indexed in Pubmed: 21914948.

26. Caughey $A B$, Cohen $A$, Lieberman $E$, et al. Rate of uterine rupture during a trial of labor in women with one or two prior cesarean deliveries. Am J Obstet Gynecol. 1999; 181(4): 872-876, doi: 10.1016/s00029378(99)70317-0, indexed in Pubmed: 10521745.

27. Landon MB, Spong CY, Thom E, et al. National Institute of Child Health and Human Development Maternal-Fetal Medicine Units Network. Risk of uterine rupture with a trial of labor in women with multiple and single prior cesarean delivery. Obstet Gynecol. 2006; 108(1): 12-20, doi: 10.1097/01.AOG.0000224694.32531.f3, indexed in Pubmed: 16816050.

28. Kaplan B, Royburt M, Peled Y, et al. Routine revision of uterine scar after prior cesarean section. Acta Obstetricia et Gynecologica Scandinavica. 1994; 73(6): 473-475, doi: 10.3109/00016349409013434.

29. Gemer O, Segal S, Sassoon E. Detection of scar dehiscence at delivery in women with prior cesarean section. Acta Obstet Gynecol Scand. 1992; 71(7): 540-542, indexed in Pubmed: 1332375.

30. Spaans W, Vliet Lv, Röell-Schorer E, et al. Trial of labour after two or three previous caesarean sections. European Journal of Obstetrics \& Gynecology and Reproductive Biology. 2003; 110(1): 16-19, doi: 10.1016/s0301-2115(03)00082-4.

31. Silver RM, Landon MB, Rouse DJ, et al. National Institute of Child Health and Human Development Maternal-Fetal Medicine Units Network. Maternal morbidity associated with multiple repeat cesarean deliveries. Obstet Gynecol. 2006; 107(6): 1226-1232, doi: 10.1097/01. AOG.0000219750.79480.84, indexed in Pubmed: 16738145.

32. Phipps MG, Watabe B, Clemons JL, et al. Risk factors for bladder injury during cesarean delivery. Obstet Gynecol. 2005; 105(1): 156-160, doi: 10.1097/01.AOG.0000149150.93552.78, indexed in Pubmed: 15625157.

33. Menacker F, MacDorman MF, Declercq E. Neonatal mortality risk for repeat cesarean compared to vaginal birth after cesarean (VBAC) deliveries in the United States, 1998-2002 birth cohorts. Matern Child Health J. 2010; 14(2): 147-154, doi: 10.1007/s10995-009-0551-5, indexed in Pubmed: 20044789.

34. Sentilhes $L$, Vayssière $C$, Beucher $G$, et al. Delivery for women with a previous cesarean: guidelines for clinical practice from the French College of Gynecologists and Obstetricians (CNGOF). Eur J Obstet Gynecol Reprod Biol. 2013; 170(1): 25-32, doi: 10.1016/j.ejogrb.2013.05.015, indexed in Pubmed: 23810846. 